\begin{tabular}{cc} 
http://dergipark.gov.tr/anatolianbryology & $\begin{array}{c}\text { Anatolian Bryology } \\
\text { Anadolu Briyoloji Dergisi } \\
\text { Research Article }\end{array}$ \\
DOI: 10.26672/anatolianbryology.422240 & e-ISSN:2458-8474 Online \\
\hline
\end{tabular}

\author{
Kütahya İli Ciğerotu (Marchantiophyta) Florasına Katkılar (Türkiye) \\ * İsa GÖKLER ${ }^{1}$ \\ Dokuz Eylül Üniversitesi, Fen Fakültesi, Biyoloji Bölümü, 35390 Buca - İzmir.
}

\begin{tabular}{lll}
\hline \hline Received:09.05.2018 & Revised:28.06.2018 & Accepted:06.06.2018 \\
\hline \hline
\end{tabular}

\title{
$\ddot{\mathbf{O} z}$
}

Bu çalışmada Kütahya İli ciğerotları florasının son durumu araştırılmıştır. Ciğerotu örnekleri çalışma bölgesinden Mart 2014 ile Aralık 2017 tarihleri arasındaki dönemde toplanmıştır. Tayin işlemleri sonucunda, Marchantiopsida (Hepaticopsida) sınıfına bağlı olan bu bitki grubundan 23 ciğerotu türü rapor edilmiş bulunmaktadır. Bu türlerden 7 tanesi (Targionia hypophylla L., Plagiochasma rupestre (J.R. Forst. et G. Forst.) Steph., Reboulia hemisphaerica (L.) Raddi, Metzgeria conjugata Lindb., Lophocolea heterophylla (Schrad.) Dumort., Scapania undulata (L.) Dumort. ve Lejeunea cavifolia (Ehrh.) Lindb.) Kütahya İli için yeni olup ilk kez belirlenmiş durumdadır.

Anahtar Kelimeler: Ciğerotları, Marchantiophyta, Flora, Kütahya, Türkiye.

\section{Contributions to the liverwort (Marchantiophyta) flora of Kütahya Province (Turkey)}

\begin{abstract}
In this study, the last state of liverworts flora of Kütahya province was investigated. Liverwort specimens were collected from study areas between March 2014 and December 2017. At the end of the of identification process, 23 liverworts species have been reported from this plant group belonging to the class Marchantiopsida (Hepaticopsida). 7 of them (Targionia hypophylla L., Plagiochasma rupestre (J.R. Forst. et G. Forst.) Steph., Reboulia hemisphaerica (L.) Raddi, Metzgeria conjugata Lindb., Lophocolea heterophylla (Schrad.) Dumort., Scapania undulata (L.) Dumort. and Lejeunea cavifolia (Ehrh.) Lindb.) are new and determined for the first time from Kütahya province.
\end{abstract}

Key words: Liverworts, Marchantiophyta, Flora, Kütahya, Turkey.

\section{Giriş}

Türkiye'nin İç Batı Anadolu kısmında yer alan Kütahya İli'nin; doğusunda Eskişehir ve Afyonkarahisar, güneyinde Uşak, batısında Balıkesir ve Manisa ile kuzeyinde Bursa ve Bilecik İlleri bulunmaktadır (Şekil 1). İl, ülkemiz florasında ana fitocoğrafik bölümler olan Akdeniz, Avrupa - Sibirya ve İran - Turan bölgelerinin kesişme noktasında bulunması nedeniyle sayısal yönden yüksek bir biyolojik çeşitliliğe sahiptir. Vejetasyon ve orman örtüsü yönünden de zengin olan çalışma bölgesinde;
Pinus nigra J.F. Arnold., P. brutia Ten., P. sylvestris L., Quercus cerris L., Q. coccifera L., Cedrus libani A. Rich., Juniperus ssp. and Castanea sativa Mill. gibi ağaç türleri yaygındır. Ehrami Karaçam olarak bilinen, Pinus nigra Arnold. subsp. pallasiana (Lamb.) Holmboe var. pyramidata (Acatay) Yaltırık taksonu ise Kütahya İli'ne has olan ve dar yayılışlı özelliğe sahip bir endemik olarak dikkat çekmektedir (Ünald1, 2004). Belirtilen dominant bitkilerce oluşturulan gölgelenme ve nemli ortam şartları nedeniyle, diğer bryofit türleri gibi ciğerotları da böyle orman altları ve ağaç

\footnotetext{
* Corresponding author: isa.gokler@gmail.com

(C) 2018 All rights reserved / Tüm haklarl saklıdır.

To cite this article: Gökler I. 2018. Contributions to the liverwort (Marchantiophyta) flora of Kütahya Province (Turkey). Anatolian Bryology. 4(1): 31-35.
} 
gövdelerini büyük oranda yaşama alanı seçmekte ve canlılıklarını koruyabilmektedirler. Çalışmalar sırasında araştırma alanı olarak ağırlık verilen ve daha dikkatle taranan habitatlar, gölgelenme ve nemin korunduğu bölümler olmuş ve elde edilen verilerin çoğu bu özellikteki habitatlardan toplanarak rapor edilmiştir.

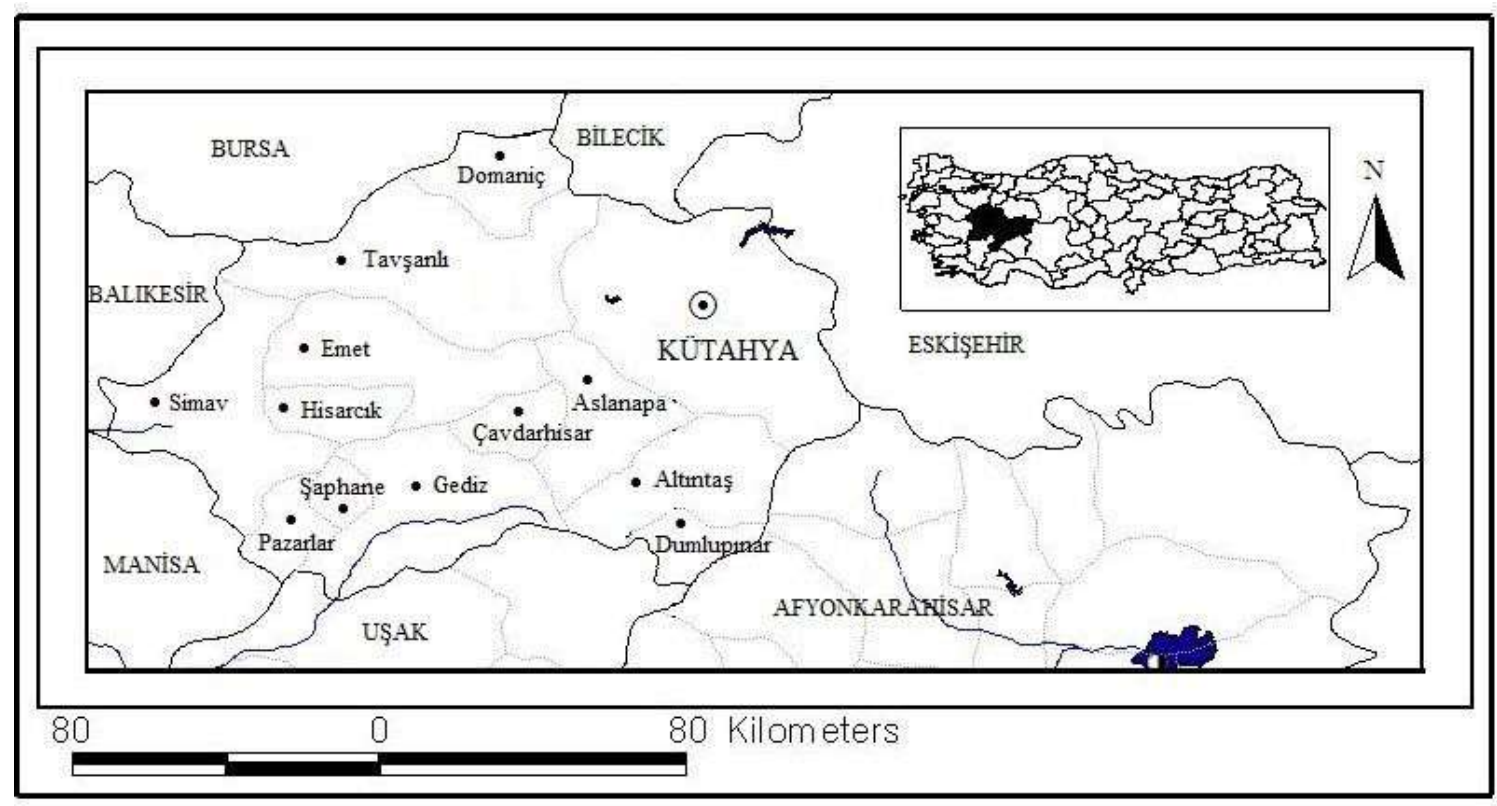

Şekil 1: Araştırma alanı olan Kütahya İli'nin coğrafik konumu.

Kütahya İli'nde yayılış gösterdiği belirlenen ilk ciğerotu örneği, Marchantia polymorpha L. türüdür (Walther, 1967). Bu kayıttan sonra, 1990'l1 yıllara kadar araştırma bölgesinden floramıza yeni bir katkı yapılamamıştır. Batı Anadolu İlleri'nin çoğundan toplanan örnekleri kapsayan ve 1992 yılında yayınlanan bir araştırma (Gökler, 1992) ile Kütahya İli için yeni olan 7 ciğerotu türü daha belirlenmiştir. Rapor edilen Metzgeria furcata (L.) Dumort., Pellia endiviifolia (Dicks.) Dumort., Plagiochila porelloides (Torrey ex Nees) Lindenb., Lophocolea bidentata (L.) Dumort., Porella cordaeana (Huebener) Moore, $P$. platyphylla (L.) Pfeiff. ve Frullania dilatata (L.) Dumort. türleri ile toplam ciğerotu sayısı 8 olmuştur. $\mathrm{Bu}$ bölgeye odaklanarak yapılan en detaylı çalışma Gökler ve Öztürk (1994) tarafindan gerçekleştirilmiştir. Belirtilen araştırma makalesi ile Kütahya Ciğerotları için yeni kayıt olarak 8 tür (Conocephalum conicum (L.) Underw., Lunularia cruciata (L.) Lindb., Marsupella emarginata (Ehrh.) Dumort., Chiloscyphus polyanthos (L.) Corda, Scapania compacta (A. Roth.) Dumort., Radula complanata (L.) Dumort., $R$. lindenbergiana Gottsche ex Hartm. ve Porella obtusata (Taylor) Trevis.) daha belirlenmiş olup günümüze kadar bilinen toplam sayı 16 olmuştur. Bu araştırmadan sonra yakın çevre illerinde de ciğerotları açısından örnekleme çalışmaları (Gökler ve Özenoğlu, 1999, Gökler, 2015, Gökler, 2017) yapılırken, Kütahya sınırları içindeki uygun habitatlardan da bitki örnekleri toplamaya devam edilmiştir. $\mathrm{Bu}$ arazi çalışmaları ile elde edilen ciğerotu örnekleri üzerinde gerekli incelemeler yapılmış, dağılım karakteristikleri ve sistematik teşhisleri sonuçlandırılmıştır. Ortaya çıkan floristik analiz verilerinin değerlendirilmesi ve Kütahya İli'nin bu bitkiler açısından son durumunun belirlenmesi araştırmanın temel amacını oluşturmaktadır.

\section{Materyal ve Yöntem}

Çalışmaya konu olan ciğerotu örnekleri Kütahya İli sınırları içinde yer alan ve Henderson (1961) Türkiye Kareleme Sistemi'ne göre B6 karesinde bulunan, ekolojik yönden uygun lokalitelerden Mart 2014 ile Aralık 2017 tarihleri arasındaki dönemde toplanmıştır. Araziden örneklerin alınması için çoğunlukla, bu bitki grubuna iklim şartları açısından en uygun olan İlkbahar ve Sonbahar mevsimleri seçilmiştir. Bitkiler belirlendikleri noktalarda, tayinleri için önemli olan renklerini gölgelemeyecek şekilde üstlerinde yer alan toprak ve çamurdan arındırılmışlardır. Plastik torbalarda laboratuvara getirilen materyal iki gruba ayrılmıştır. İlk grup üzerine basınç uygulanmayan özel herbaryum zarflarında, ışık alan ve hava akımı olmayan bir odada kurumaya birakılırken, özellikle tallus yapılı örneklerden oluşan diğer grup ise morfolojik özelliklerin tam belirlenmesi ve anatomik kesitler için yaş olarak muhafaza edilmiştir. Dünyada ve Henderson Türkiye Kareleme Sistemine göre (Henderson, 1961) ülkemizdeki dağılımlarının belirlenmesi ve tayin karakteristiklerinin elde edilmesi için çeşitli flora listeleri, kaynak kitaplar ve çalışma bölgesine yakın sonuçları içeren makalelerden (Henderson ve Prentice (1969), Watson (1981), Smith (1996), Grolle ve Long (2000), Söderström vd. (2002), Kürschner ve Erdağ (2005), Özenoğlu Kiremit ve Keçeli (2009), Walther (1967, 1970), Crundwell ve Nyholm (1979), Gökler ve 
Öztürk (1991, 1994), Gökler (1992, 2015, 2017) ve Gökler ve Özenoğlu (1999) yararlanılmıştır. Bitki listesi, Grolle ve Long (2000) tarafindan oluşturulan sisteme göre düzenlenmiştir. Tüm örnekler tayin çalışmalarının gerçekleştirildiği, Dokuz Eylül Üniversitesi Fauna ve Flora Araştırma ve Uygulama Merkezi'nde korunmaktadır.

\section{Sonuç ve Tartışma \\ Marchantiophyta \\ Marchantiopsida \\ Targioniaceae}

1. Targionia hypophylla L.

B6. Simav - Öreğler Kasabası, dere yatağı kenarlarındaki kaya yarıkları arasında, Gökler KT51, 10.03.2015.

B6. Şaphane - Gediz kavşağı, dere kenarlarındaki nemli kayaların üzerinde, Gökler KT57, 11.03.2015.

Yayılışı: Türkiye (A1,A2, B6,B7, C11, C12, C13), Akdeniz Ülkeleri ve Kanada.

\section{Aytoniaceae}

2. Plagiochasma rupestre (J.R. Forst. et G. Forst.) Steph.

B6. Gediz - Murat Dağı yolu kenarındaki nemli kayaların üzeri, Gökler KT38, 03.03.2014.

Yayılışı: Türkiye (A2, A4, B6, B7, C11, C 12), Akdeniz Ülkeleri ve Rusya.

3. Reboulia hemisphaerica (L.) Raddi

B6. Gediz - Murat Dağı yolu kenarındaki nemli kayaların üzeri, Gökler KT39, 03.03.2014.

B6. Şaphane - Gediz kavşağ nemli kayaların üzerinde, Gökler KT58, 11.03.2015.

Yayılışı: Türkiye (A4, B6, B7, B8, C11, C12, C13), Dünyanın her bölgesinde yayılışı olan kozmopolit bir türdür.

\section{Conocephalaceae}

4. Conocephalum conicum (L.) Underw.

B6. Gediz, Murat Dağı, Bayboğan Deresi kenarları, Gölgelenmiş ana kayaların üzeri, Gökler KT59, 12.03.2015.

B6. Emet, Aşağı Yumrutaş çevresi, Su Kavuştuğu mevkisi, dere kenarındaki kayalar ve toprak üzerinde, Gökler KT40, 04.03.2014

Yayılışı: Türkiye (A1, A2, A3, A4, B6.C11, C12), Avrupa, Akdeniz Ülkeleri ve Kuzey Amerika.

\section{Lunulariaceae}

5. Lunularia cruciata (L.) Lindb.

B6. Simav, Öreğler Kasabası, dere yatağı kenarları, Gökler KT52, 10.03.2015.

B6. Aslanapa - Kütahya yolu, dere kenarları, Gökler KT83, 28.09.2016.

Yayılışı: Türkiye (A1, A2, A3, A4, A5, B6, B9, C11, C12), Avrupa, Akdeniz Ülkeleri ve Avustralya.

\section{Marchantiaceae}

6. Marchantia polymorpha L.
B6. Gediz, Murat Dağı, Bayboğan Deresi kenarları, Gölgelenmiş ana kayaların üzeri, Gökler KT60, 12.03.2015.

B6. Emet, Eğrigöz Dağı, Arpa tarlası mevkisi, dere kenarlar1, Gökler KT109, 12.12.2017.

Yayılışı: Türkiye (A1, A2, A3, A4, A5, B6, B7, B8, B9, C11, C12, C13, C15), Dünyanın büyük bölümünde dağılımı olan kozmopolit bir türdür.

\section{Metzgeriaceae}

7. Metzgeria conjugata Lindb.

B6. Gediz - Uşak yolu, dere kenarları, Gökler KT39, 03.03.2014.

Yayılışı: Türkiye (A3, A4, B6, C13), Avrupa, Asya, Güney Afrika, Kuzey Amerika, Brezilya ve Yeni Zelanda.

8. M. furcata (L.) Dumort.

B6. Gediz - Uşak yolu, dere kenarları, Gökler KT41, 03.03.2014

B6. Simav - Demirci yolu kenarları, dere yatakları çevresi, KT42, 03.03.2014.

B6. Emet, Aşağı Yumrutaş çevresi, Su Kavuştuğu mevkisi, dere kenarındaki kayalar ve toprak üzerinde, Gökler KT44, 04.03.2014.

Yayılışı: Türkiye (A1. A2, A3, A4, B6, C11, C12, C13), Avrupa, Asya, Kuzey Amerika, Japonya, Avustralya ve Yeni Zelanda.

\section{Pelliaceae}

9. Pellia endiviifolia (Dicks.) Dumort.

B6. Gediz, Murat Dağı, kaynak kenarları ve dere yatakları çevresi, Gökler KT61, 12.03.2015.

Yayılışı: Türkiye (A1. A2, A3, A4, B6, B7, B9, C11, C12), Avrupa, Kafkasya, Akdeniz Ülkeleri, Japonya, Güney Kore, Çin ve Kuzey Amerika.

\section{Lophoziaceae}

10. Plagiochila porelloides (Torrey ex Nees) Lindenb. B6. Gediz, Çukurören Köyü, kaynaklar ve dere yatakları kenarları, Gökler KT78, 11.04.2016.

Yayılışı: Türkiye (A1, A2, A3, A4, B6, B7, C11, C12), Avrupa, Asya ve Kuzey Amerika.

\section{Gymnomitriaceae}

11. Marsupella emarginata (Ehrh.) Dumort.

B6. Simav, Öreğler Kasabası, dere yatağı kenarları, Gökler KT56, 10.03.2015.

Yayılışı: Türkiye (A4, B6), Avrupa, Kafkasya, Japonya ve Kuzey Amerika.

\section{Geocalycaceae}

12. Chiloscyphus polyanthos (L.) Corda

B6. Emet, Eğrigöz Dağı, Arpa tarlası mevkisi, dere kenarlar1, Gökler KT110, 12.12.2017.

Yayılış1: Türkiye (A1, A2, A4, A5, B6, C11), Avrupa, Kuzey Afrika, Japonya ve Kuzey Amerika.

\section{Geocalycaceae}

13. Lophocolea bidentata (L.) Dumort. 
B6. Gediz, Murat Dağı, kaynak kenarları ve dere yatakları çevresi, Gökler KT62, 12.03.2015.

Yayılışı: Türkiye (A1, A2, A3, A4, B6), Avrupa, Asya, Afrika, Kuzey Amerika, Küba ve Yeni Zelanda.

14. L. heterophylla (Schrad.) Dumort.

B6. Tavşanlı - Emet arası, yol kenarlarındaki gölgeli nemli alanlar, Gökler KT45, 04.03.2014.

B6. Gediz, Murat Dağı, kaynak kenarları ve dere yatakları çevresi, Gökler KT63, 12.03.2015.

Yayılışı: Türkiye (A2. A3, A4, B6), Avrupa, Tunus, Rusya, Japonya, Hindistan ve Kuzey Amerika.

\section{Scapaniaceae}

15. Scapania compacta (A.Roth.) Dumort.

B6. Simav, Öreğler Kasabası, dere yatağı kenarları, Gökler KT53, 10.03.2015.

Yayılışı: Türkiye (A1, B6), Avrupa, Kafkasya, Kuzey Afrika ve Kuzey Amerika.

16. S. undulata (L.)Dumort.

B6. Simav, Öreğler Kasabası, dere yatağı kenarları, Gökler KT54, 10.03.2015.

Yayılışı: Türkiye (A1, A4, B6, C11), Avrupa ve Kuzey Amerika.

\section{Radulaceae}

17. Radula complanata (L.) Dumort.

B6. Simav - Demirci yolu kenarları, dere yatakları çevresi, KT43, 03.03.2014.

B6. Domaniç, Güney Köyü girişi, nemli kayalar ve ağaç gövdeleri üzerinde, Gökler KT46, 05.03.2014.

Yayılışı: Türkiye (A1, A2, A4, B6, C11), Avrupa, Asya, Kuzey Afrika ve Kuzey Amerika.

18. R. lindenbergiana Gottsche. ex Hartm.

B6. Simav - Demirci yolu kenarları, dere yatakları çevresi, KT44, 03.03.2014.

Yayılışı: Türkiye (A1, A2, A3, A4, B6, C11) Avrupa, Asya ve Kuzey Amerika.

\section{Porellaceae}

19. Porella cordaeana (Huebener) Moore

B6. Simav - Demirci yolu kenarları, dere yatakları çevresi, KT45, 03.03.2014.

B6. Simav, Gölcük Karagöl çevresi, ağaç gövdeleri üzerinde, KT95, 17.01.2017.

Yayılışı: Türkiye (A1, A2, A3, A4, B6, B7, C11, C12, C13), Avrupa, Asya, Kuzey Afrika ve Kuzey Amerika. 20. P. obtusata (Taylor) Trevis.

B6. Simav - Demirci yolu kenarları, dere yatakları çevresi, KT46, 03.03.2014.

Yayılışı: Türkiye (A3, A4, B6), Avrupa, Asya ve Kuzey Afrika.

21. P. platyphylla (L.) Pfeiff.
B6. Gediz, Murat Dağı, Bayboğan Deresi kenarlarındaki kayalar ve ağaç gövdeleri üzerinde, Gökler KT64, 12.03.2015.

B6. Simav, Gölcük Karagöl çevresi, ağaç gövdeleri üzerinde, KT96, 17.01.2017.

Yayılışı: Türkiye (A1, A2, A3, A4, A5, B6, B7, B8, C11, C12, C13), Avrupa, Akdeniz Ülkeleri, Kuzey Afrika ve Kuzey Amerika.

\section{Frullaniaceae}

22. Frullania dilatata (L.) Dumort.

B6. Simav - Demirci yolu kenarları, dere yatakları çevresindeki ağaç gövdeleri üzerinde, KT47, 03.03.2014.

Simav, Gölcük Karagöl çevresi, ağaç gövdeleri üzerinde, KT97, 17.01.2017.

Yayılışı: Türkiye (A1, A2, A3, A4, A5, B6, C11, C12, C13), Avrupa, Asya ve Kuzey Afrika.

\section{Lejeuneaceae}

23. Lejeunea cavifolia (Ehrh.) Lindb.

B6. Domaniç, Güney Köyü girişi, nemli kayalar ve ağaç gövdeleri üzerinde, Gökler KT47, 05.03.2014.

Yayılışı: Türkiye (A1, A2, A3, A4, B6, B7, C11), Avrupa, Asya, Kuzey Afrika ve Kuzey Amerika.

Yapılan araştırma ile gerçekleştirilen tayin çalışmaları sonucu, Kütahya İli sınırları içinde Marchantiopsida (Hepaticopsida) sınıfina bağlı 13 familyaya ait 23 ciğerotu türünün (9 adedi tallus, 14 tanesi yapraksı yapılı) yayılış gösterdiği ortaya çıkarılmıştır. Belirlenen bu türlerden 7 tanesi (Targionia hypophylla L., Plagiochasma rupestre (J.R. Forst. et G. Forst.) Steph., Reboulia hemisphaerica (L.) Raddi, Metzgeria conjugata Lindb., Lophocolea heterophylla (Schrad.) Dumort., Scapania undulata (L.)Dumort. ve Lejeunea cavifolia (Ehrh.) Lindb.) Kütahya İli florası için yeni olma özelliği taşımakta olup ilk kez rapor edilmektedirler.

Türkiye Florası, damarlı bitkiler yönünden zengin takson sayısı ve yüksek endemizm oranı ile dikkat çeken bir karakteristiğe sahiptir. Ülkemiz bryofitleri de, tohumlu bitkilerden sonra floramıda en fazla biyoçeşitliliği barındıran bitki grubu durumundadır. $\mathrm{Bu}$ nedenle, Marchantiophyta türleri açısından hiç veri elde edilememiş olma özelliği taşıyan veya üzerinde az çalışılmış bulunan ve ekolojik yönden uygun habitatlara sahip bölgelerimizde yapılacak benzer araştırmalarla, yeni sonuçlar elde edilebileceği ve Türkiye biyoçeşitliliğinin önemli bir parçası olan ciğerotları floramı katkılar sağlanabileceği düşünülmektedir.

\section{Kaynaklar}

Crundwell C.C. and Nyholm E. 1979. Some additions to the bryophyte flora of Turkey I. Hepaticae. Journal of Bryology. 10: 479-489.

Gökler İ. 1992. Batı Anadolu Ciğerotları Üzerine Bir Araştırma. Doğa Türk Botanik Dergisi. 16 (1): 1-8.

Gökler İ. 2015. Çanakkale İli Boynuzsu Otları ve Ciğerotları Üzerine Taksonomik ve Ekolojik Bir Araştırma. Anadolu Doğa Bilimleri Dergisi. 6 (2): 35-43. 
Gökler İ. 2017. Contributions to the Liverworts Flora of Uşak Province. Anatolian Bryology. 3 (1): 19-24.

Gökler İ. and Özenoğlu H. 1999. Kazdağı Milli Parkı ve Çevresi Ciğerotlarının Taksonomisi ve Ekolojisi. Ekoloji Çevre Dergisi. 30: 22-26.

Gökler İ. and Öztürk M. 1991. Liverworts of Turkey and their position in Southwest Asia. Candollea. 46: 359366.

Gökler İ. and Öztürk M. 1994. Kütahya İli Ciğerotları Üzerinde Taksonomik ve Ekolojik Bir Araştırma. Ege Üniversitesi Fen Fakültesi Dergisi. 16 (1): 1525-1529.

Grolle R. and Long D.G. 2000. An Annotated Check-List of the Hepaticae and Anthocerotae of Europae and Macaronesia. Journal of Bryology. 22: 103-140.

Henderson, D.M. 1961. Contributions to the bryophyte flora of Turkey. IV. Notes from Royal Botanic Garden Edinburgh. 23: 263-278.

Henderson, D.M. and Prentice, H. 1969. Contributions to the bryophyte flora of Turkey.VIII. Notes from Royal Botanic Garden Edinburgh. 29: 235-262.

Kürschner H. and Erdağ A. 2005. Bryophytes of Turkey: An Annotated Reference List of the Species with Synonyms from the Recent Literature and an Annotated List of Turkish Bryological Literature. Turkish Journal of Botany. 29: 95-154.

Özenoğlu Kiremit H. and Keçeli T. 2009. An Annotated Check-list of the Hepaticae and Anthocerotae of Turkey. Cryptogamie Bryologie. 30 (3): 343-356.

Smith A.E. 1996. The Liverworts of Britain and Ireland. Cambridge University Press. Cambridge.

Söderström L. Urmi E. Vana J. 2002. Distribution of Hepaticae and Anthocerotae in Europe and Macaronesia. Lindbergia. 27: 3-47.

Ünaldı Ü.E. 2004. Nesli Tehlikedeki Ağaç: Ehrami Karaçam (Pinus nigra ssp. pallasiana var. pyramidata). Fırat Üniversitesi Sosyal Bilimler Dergisi. 14 (1): 67-80.

Walther K. 1967. Beitrage zur Moosflora Westanatoliens I. Mitteilungen aus dem Staatsinstitut für Allgemeine Botanik in Hamburg. 12: 129-186.

Walther K. 1970. Beitrage zur Moosflora Westanatoliens II. Mitteilungen aus dem Staatsinstitut für Allgemeine Botanik in Hamburg. 13: 167-180.

Watson E.V. 1981. British Mosses and Liverworts. Cambridge University Press. Cambridge. 